\title{
Ka-Band Slot-Microstrip-Covered and Waveguide-Cavity-Backed Monopulse Antenna Array
}

\author{
Li-Ming Si, ${ }^{1}$ Yong Liu, ${ }^{1}$ Yongjun Huang, ${ }^{2}$ and Weiren $\mathrm{Zhu}^{3}$ \\ ${ }^{1}$ Beijing Key Laboratory of Millimeter Wave and Terahertz Technology, Department of Electronic Engineering, \\ School of Information and Electronics, Beijing Institute of Technology, Beijing 100081, China \\ ${ }^{2}$ Key Laboratory of Broadband Optical Fiber Transmission \& Communication Networks, School of Communication and \\ Information Engineering, University of Electronic Science and Technology of China, Chengdu 611731, China \\ ${ }^{3}$ Advanced Computing and Simulation Laboratory $(A \chi L)$, Department of Electrical and Computer Systems Engineering, \\ Monash University, Clayton, VIC 3800, Australia
}

Correspondence should be addressed to Li-Ming Si; lms@bit.edu.cn

Received 6 September 2013; Revised 18 December 2013; Accepted 5 January 2014; Published 10 March 2014

Academic Editor: P. Mohanan

Copyright (C) 2014 Li-Ming Si et al. This is an open access article distributed under the Creative Commons Attribution License, which permits unrestricted use, distribution, and reproduction in any medium, provided the original work is properly cited.

\begin{abstract}
A slot-microstrip-covered and waveguide-cavity-backed monopulse antenna array is proposed for high-resolution tracking applications at Ka-band. The monopulse antenna array is designed with a microstrip with $2 \times 32$ slots, a waveguide cavity, and a waveguide monopulse comparator, to make the structure simple, reduce the feeding network loss, and increase the frequency bandwidth. The $2 \times 32$ slot-microstrip elements are formed by a metal clad dielectric substrate and slots etched in the metal using the standard printed circuit board (PCB) process with dimensions of $230 \mathrm{~mm} \times 10 \mathrm{~mm}$. The proposed monopulse antenna array not only maintains the advantages of the traditional waveguide slot antenna array, but also has the characteristics of wide bandwidth, high consistence, easy of fabrication, and low cost. From the measured results, it exhibits good monopulse characteristics, including the following: the maximum gains of sum pattern are greater than $24 \mathrm{~dB}$, the $3 \mathrm{~dB}$ beamwidth of sum pattern is about 2.2 degrees, the sidelobe levels of the sum pattern are less than $-18 \mathrm{~dB}$, and the null depths of the difference pattern are less than $-25 \mathrm{~dB}$ within the operating bandwidth between $33.65 \mathrm{GHz}$ and $34.35 \mathrm{GHz}$ for VSWR $\leq 2$.
\end{abstract}

\section{Introduction}

Millimeter-wave monopulse antenna arrays have received considerable attention in the radar tracking systems owing to their ultrahigh resolution $[1,2]$. Waveguide slot antenna arrays [3] or microstrip antenna arrays $[4,5]$ are commonly used in traditional monopulse tracking systems. Waveguide slot antenna arrays possess several unique advantages, such as low loss, low coupling effect, low cross-polarization, high radiation efficiency, high polarization purity, high frequency operation, and high power handling capability, but they are of narrow bandwidth and high cost and not suitable for mass production [6-9]. Microstrip antenna arrays have been widely used in monopulse system, showing benefits including high integration capability, low cost, and ease of mass production $[4,5]$. However, they have difficulty in achieving low sidelobe levels and high radiation efficiencies due to the strong mutual coupling and spurious radiation among the monopulse comparator, feed network, and radiation elements [10]. Furthermore, the loss in a microstrip line becomes much more significant due to the high conductor loss, dielectric loss, and radiation loss in the millimeter wave and upper bands $[11,12]$. To overcome the drawbacks of the conventional waveguide slot and microstrip antenna arrays, dielectric-covered slot arrays were investigated by Montisci et al. [13-16] and Zheng et al. [17], but they did not tell about the monopulse characteristics. Recently, substrate integrated waveguide (SIW) technology based monopulse antenna array is proposed by Cheng et al. [18]. Since SIW can not only preserve the advantages of conventional rectangular waveguide but also be implemented with printed circuit board (PCB) process, the monopulse comparator and the radiation elements of this array are all integrated on single dielectric substrate [18]. 


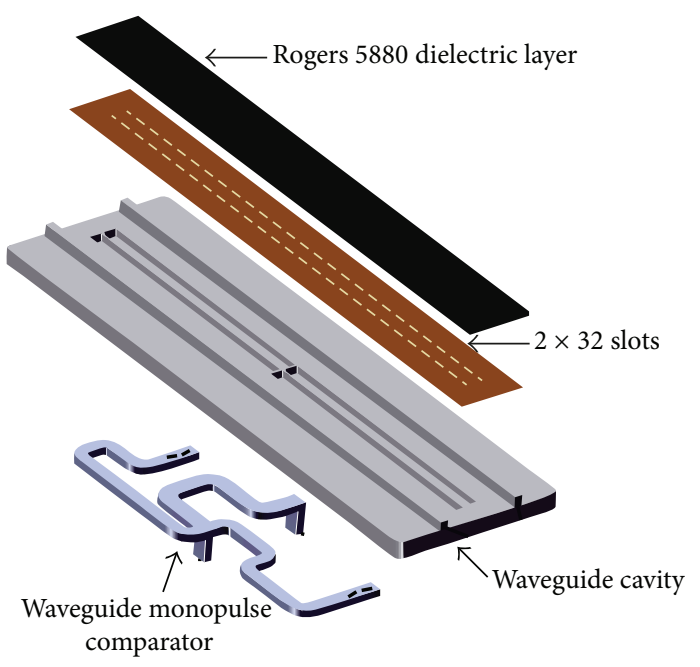

(a)

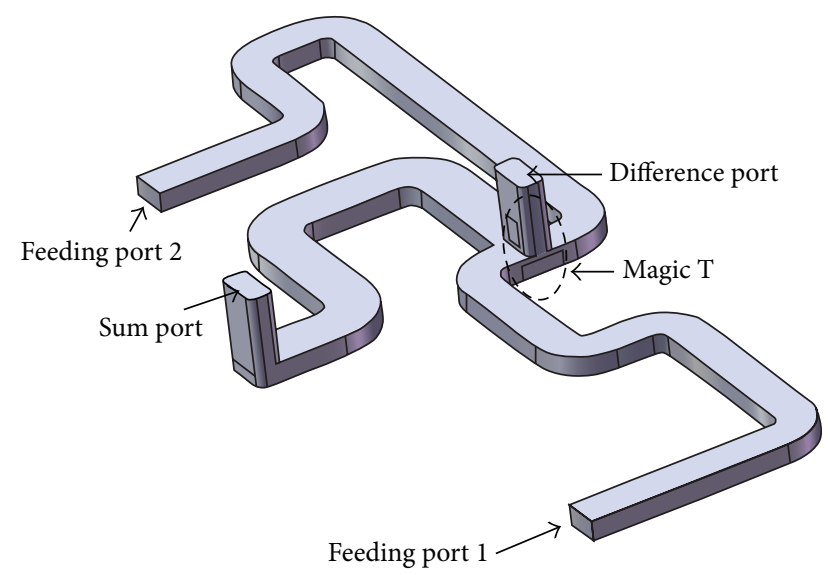

(b)

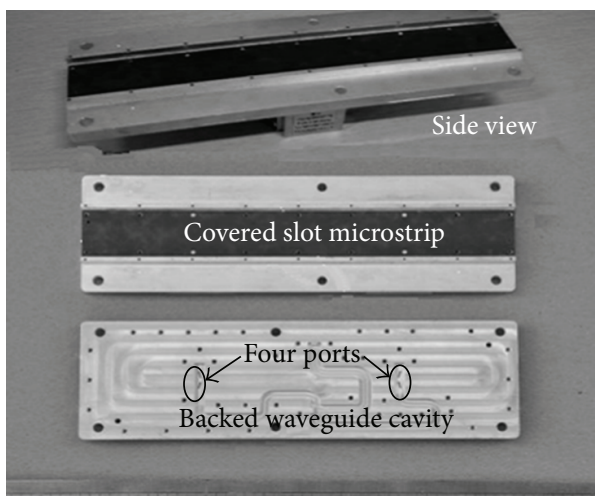

(c)

Figure 1: Structure of the monopulse antenna array. (a) Exploded view, (b) waveguide monopulse comparator, and (c) prototype.

This work experimentally investigates a Ka-band slotmicrostrip-covered and waveguide-cavity-backed monopulse antenna array composed of a microstrip with $2 \times$ 32 slots, a waveguide cavity, and a waveguide monopulse comparator. Experimental results exhibit good monopulse characteristics in terms of wide bandwidth, maximum gains, $3 \mathrm{~dB}$ beamwidths, sidelobe levels, and null depths, which combines the advantages of the waveguide slot antenna array and microstrip antenna array while eliminating their disadvantages.

\section{Design, Fabrication, and Test}

The structure of the monopulse antenna array is shown in Figure 1, which consists of a microstrip with $2 \times 32$ slots, a waveguide cavity, and a waveguide monopulse comparator. The copper slot microstrip $(0.018 \mathrm{~mm}$ thick $)$ is fabricated on a Rogers 5880 dielectric layer $(0.254 \mathrm{~mm}$ thick, $\varepsilon=2.2)$. Four subarrays are connected to the four ports of the feed network. The waveguide monopulse comparator is realized by using a magic-T to obtain a sum and difference feeding network, as shown in Figure 1(b). Each subarray was formed by $1 \times 16$ slot-microstrip elements with a Taylor amplitude distribution
[19]. In this study, the centre distance between two slots is $\lambda_{g} / 2(6.48 \mathrm{~mm})$, where $\lambda_{g}$ is the guided wavelength. The slots are placed at a quarter of the guided wavelength $\left(\lambda_{g} / 4\right)$ from the shorted wall. They are $0.6 \mathrm{~mm}$ in width and $3.2 \mathrm{~mm}$ in length, and the approximate offset value from the waveguide centreline is calculated at $34 \mathrm{GHz}$ using the equivalent circuit mode or termed Elliott's method [20, 21]. Elliott's method has been successfully used for waveguide slot antenna arrays [22-28], although it yields the offset value to be approximately effective only. In order to get more accurate offset value and fully account for the coupling effect, it is necessary to optimize the monopulse antenna array by fullwave simulation. Table 1 lists the final optimized offset values using both Elliott's method and FEM based 3D full-wave simulator Ansys HFSS.

The size of the groove guide in the waveguide cavity is $2.74 \mathrm{~mm} \times 5.48 \mathrm{~mm}$. The height of the metal walls is $4 \mathrm{~mm}$. The cross-section dimension of the waveguide in this design is $3.556 \mathrm{~mm} \times 7.112 \mathrm{~mm}$ (WR-28). Four aperturecoupled slots (with $3.6 \mathrm{~mm} \times 0.6 \mathrm{~mm}$ ) are used to excite the $2 \times 32$ slot-microstrip elements at the feeding ports 1 and 2 of the monopulse comparator, as shown in Figure 1. For the monopulse antenna array, loss is unavoidable 
TABLE 1: Offset value of the subarray slots (16 slot-microstrip elements) from the waveguide centreline, unit in millimeter.

\begin{tabular}{|c|c|c|c|c|c|c|c|c|c|c|c|c|c|c|c|c|}
\hline Number & 1 & 2 & 3 & 4 & 5 & 6 & 7 & 8 & 9 & 10 & 11 & 12 & 13 & 14 & 15 & 16 \\
\hline Offset & 0.29 & 0.30 & 0.31 & 0.33 & 0.36 & 0.39 & 0.43 & 0.47 & 0.51 & 0.55 & 0.58 & 0.61 & 0.64 & 0.65 & 0.67 & 0.67 \\
\hline
\end{tabular}

in the feeding network and dielectric. However, in our case, the loss is limited by the metal waveguide based monopulse comparator and very low loss tangent (0.0009) of Rogers 5880 dielectric layer in our design. Note that this design may lead to mass production, reduce the cost, and increase the frequency bandwidth as compared with the standard slotted waveguide technology. The monopulse antenna array is assembled by brazing the waveguides (including waveguide cavity and waveguide monopulse comparator) and using conductive adhesive to adhere the copper slot microstrip and waveguide cavity together. To avoid weak electrical contact between PCB and waveguides during the annealing process, screws are also used to secure stem attachment between them.

Figure 2 shows the measured VSWR of the sum port and the difference port. The results show that the measured bandwidth (VSWR $\leq 2$ ) of the monopulse antenna array is $700 \mathrm{MHz}$ (from $33.65 \mathrm{GHz}$ to $34.35 \mathrm{GHz}$ ) for both the sum port and the difference port. The measured normalized Eplane sum and difference radiation patterns and H-plane sum radiation pattern at $34 \mathrm{GHz}$ are shown in Figure 3 . The sum pattern exhibits a 2.2-degree $3 \mathrm{~dB}$ beamwidth and $-18 \mathrm{~dB}$ sidelobe level. The normalized null depth of the difference pattern is less than $-40 \mathrm{~dB}$. Table 2 summarizes the measured maximum gains and the null depths at different frequencies. It is seen that the maximum gains of sum pattern are greater than $24 \mathrm{dBi}$ and the null depths of the difference pattern are less than $-25 \mathrm{dBi}$ within the operating bandwidth between $33.65 \mathrm{GHz}$ and $34.35 \mathrm{GHz}$ for VSWR $\leq 2$. The radiation efficiency of the Ka-band slot-microstrip-covered and waveguide-cavity-backed monopulse antenna array is $85.3 \%$ which is significantly higher than that of the microstrip antenna array.

Such Ka-band slot-microstrip-covered and waveguidecavity-backed monopulse antenna array has better performance in bandwidth than that in conventional waveguide slot monopulse antenna arrays, better sidelobe levels and radiation efficiency, and high polarization purity than those in conventional microstrip monopulse antenna arrays. For instance, the bandwidth of the conventional aperture-coupled waveguide slot monopulse is just 1\% [11], while it is greater than $2 \%$ for the proposed monopulse antenna. In addition, the radiation efficiency of the conventional microstrip monopulse antenna array is about $40 \%$, whilst it is greater than $80 \%$ for the proposed monopulse antenna. The first reason is that the slotmicrostrip-covered dielectric above a metal ground can increase the impedance bandwidth of the monopulse antenna array. Furthermore, waveguide has lower loss and is more suitable for high frequency transmission than microstrip line.

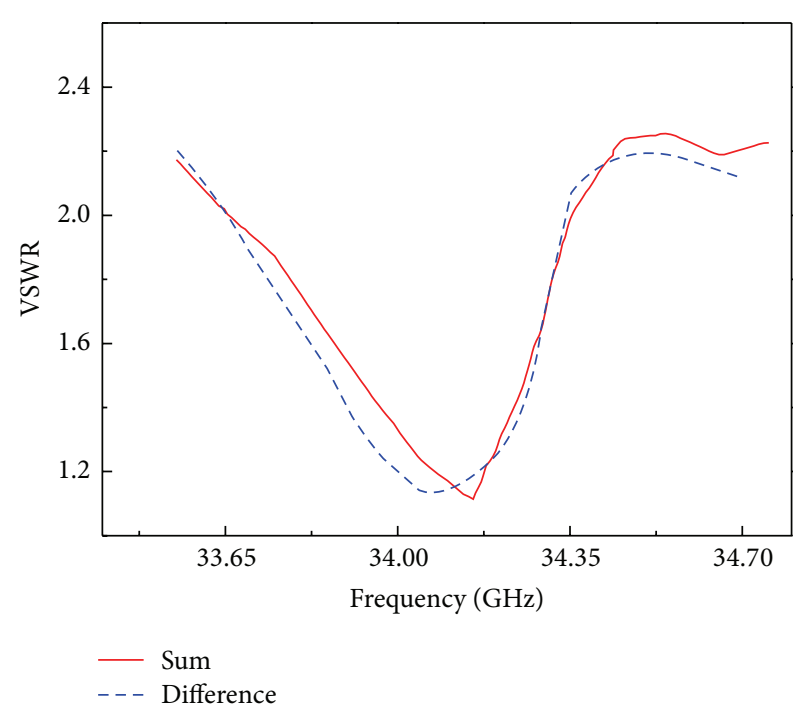

FIgURE 2: Measured VSWR.

TABLE 2: Measured maximum gains and the null depths at different frequencies.

\begin{tabular}{lcc}
\hline$f(\mathrm{GHz})$ & Maximum gain $(\mathrm{dBi})$ & Null depth $(\mathrm{dBi})$ \\
\hline 33.65 & 25.24 & -28.1 \\
33.8 & 24.79 & -37.3 \\
34 & 24.84 & -29.9 \\
34.2 & 24.51 & -26 \\
34.35 & 24.55 & -25.7 \\
\hline
\end{tabular}

\section{Conclusion}

Ka-band slot-microstrip-covered and waveguide-cavitybacked monopulse antenna array has been designed and experimentally investigated in this paper. The measured results show that the maximum gains are greater than $24 \mathrm{dBi}$, the $3 \mathrm{~dB}$ beamwidths are about 2.2 degrees, the sidelobe levels are less than $-18 \mathrm{~dB}$, and the null depths are less than $-25 \mathrm{dBi}$, during the $700 \mathrm{MHz}$ operating frequencies. These results demonstrate that the slot-microstrip-covered and waveguide-cavity-backed monopulse antenna array has a broad bandwidth, high consistence, ease of fabrication, and low cost, and it can be successfully applied to millimeter-wave monopulse radar systems.

\section{Conflict of Interests}

The authors declare that there is no conflict of interests regarding the publication of this paper. 


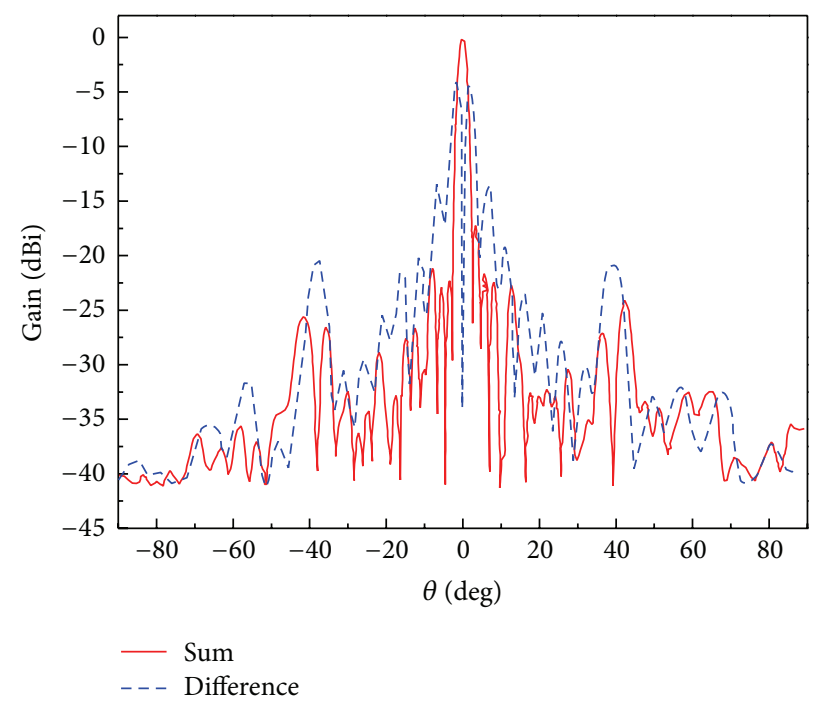

(a)

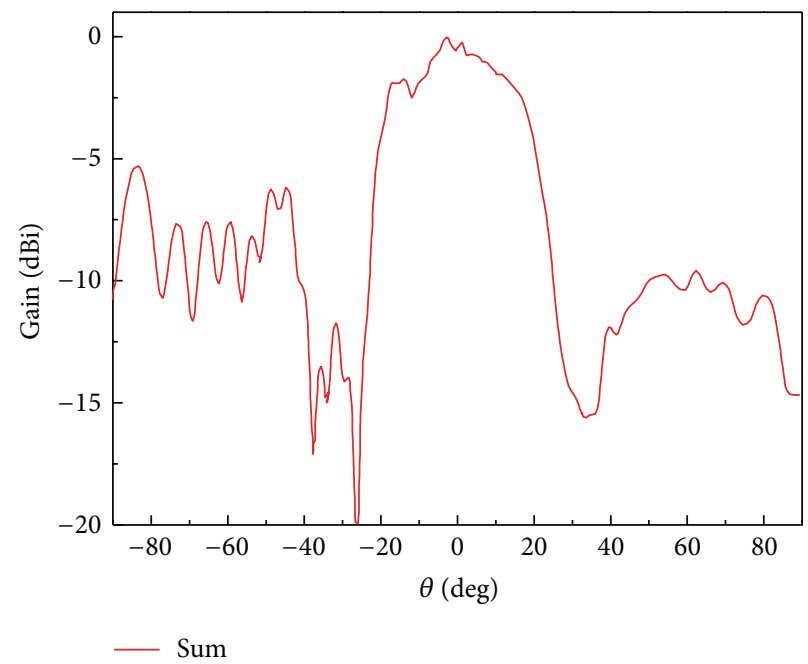

(b)

Figure 3: Measured normalized (a) E-plane sum and difference radiation patterns and (b) H-plane sum radiation pattern at 34 GHz.

\section{Acknowledgments}

This work was supported by the National Natural Science Foundation of China (Grant nos. 61307128 and 61371047), the Specialized Research Foundation for the Doctoral Program of Higher Education of China (Grant no. 20131101120027), and the Basic Research Foundation of Beijing Institute of Technology (Grant no. 20120542015).

\section{References}

[1] D. Barton, "History of monopulse radar in the US," IEEE Aerospace and Electronic Systems Magazine, vol. 25, no. 3, pp. C4-C15, 2010.

[2] W. Rosloniec, "Application of the total least square ESPRIT method to estimation of angular coordinates of moving objects," International Journal of Antennas and Propagation, vol. 2010, Article ID 548953, 9 pages, 2010.

[3] R. R. Kinsey, "An edge-slotted waveguide array with dual-plane monopulse," IEEE Transactions on Antennas and Propagation, vol. 47, no. 3, pp. 474-481, 1999.

[4] H. Wang, D. G. Fang, and X. G. Chen, "A compact single layer monopulse microstrip antenna array," IEEE Transactions on Antennas and Propagation, vol. 54, no. 2, pp. 503-509, 2006.

[5] S.-G. Kim and K. Chang, "Low-cost monopulse antenna using bi-directionally-fed microstrip patch array," Electronics Letters, vol. 39, no. 20, pp. 1428-1429, 2003.

[6] J. Hirokawa and M. Ando, "Efficiency of 76-GHz post-wall waveguide-fed parallel-plate slot arrays," IEEE Transactions on Antennas and Propagation, vol. 48, no. 11, pp. 1742-1745, 2000.

[7] G. Montisci, M. Musa, and G. Mazzarella, "Waveguide slot antennas for circularly polarized radiated field," IEEE Transactions on Antennas and Propagation, vol. 52, no. 2, pp. 619-623, 2004.

[8] T. Suzuki, J. Hirokawa, and M. Ando, "Iteration-free design of waveguide slot array with cavities," IEEE Transactions on Antennas and Propagation, vol. 58, no. 12, pp. 3891-3897, 2010.
[9] S. R. Rengarajan, "Genetic algorithm optimization of a planar slot array using full wave method-of-moments analysis," International Journal of $R F$ and Microwave Computer-Aided Engineering, vol. 23, no. 4, pp. 430-436, 2013.

[10] H. Singh, H. J. Sneha, and R. M. Jha, "Mutual coupling in phased arrays: a review," International Journal of Antennas and Propagation, vol. 2013, Article ID 348123, 23 pages, 2013.

[11] Y. Liu, L.-M. Si, M. Wei et al., "Some recent developments of microstrip antenna," International Journal of Antennas and Propagation, vol. 2012, Article ID 428284, 10 pages, 2012.

[12] L. M. Si, Y. Liu, H. D. Lu, H. J. Sun, X. Lv, and W. Zhu, "Experimental realization of high transmittance $\mathrm{THz}$ 90-degree-bend waveguide using EMXT structure," IEEE Photonics Technology Letters, vol. 25, no. 5, pp. 519-522, 2013.

[13] G. Montisci, Z. S. Jin, M. C. Li et al., "Design of multilayer dielectric cover to enhance gain and efficiency of slot arrays," International Journal of Antennas and Propagation, vol. 2013, Article ID 917676, 6 pages, 2013.

[14] Z. S. Jin, G. Montisci, G. A. Casula, H. Yang, and J. Q. $\mathrm{Lu}$, "Efficient evaluation of the external mutual coupling in dielectric-covered waveguide slot antennas," International Journal of Antennas and Propagation, vol. 2012, Article ID 491242, 7 pages, 2012.

[15] G. A. Casula and G. Montisci, "Design of dielectric-covered planar arrays of longitudinal slots," IEEE Antennas and Wireless Propagation Letters, vol. 8, pp. 752-755, 2009.

[16] G. A. Casula, G. Mazzarella, and G. Montisci, "Design of slot arrays in waveguide partially filled with dielectric slab," Electronics Letters, vol. 42, no. 13, pp. 730-731, 2006.

[17] Y. Zheng, G. Yang, and S. Song, "Design of a single-layer waveguide slot array antenna," in Proceedings of the International Workshop on Microwave and Millimeter Wave Circuits and System Technology, pp. 1-3, Chengdu, China, 2012.

[18] Y. J. Cheng, W. Hong, and K. Wu, " $94 \mathrm{GHz}$ substrate integrated monopulse antenna array," IEEE Transactions on Antennas and Propagation, vol. 60, no. 1, pp. 121-129, 2012. 
[19] T. T. Taylor, "Design of line-source antennas for narrow beamwidth and low side lobes," IRE Transactions on Antennas and Propagation, vol. 3, pp. 16-28, 1955.

[20] R. S. Elliott, "An improved design procedure for small arrays of shunt slots," IEEE Transactions on Antennas and Propagation, vol. 31, no. 1, pp. 48-53, 1983.

[21] G. J. Stern and R. S. Elliott, "Resonant length of longitudinal slots and validity of circuit representation: theory and experiment," IEEE Transactions on Antennas and Propagation, vol. 33, no. 11, pp. 1264-1271, 1985.

[22] L. G. Josefsson, "Analysis of longitudinal slots in rectangular waveguides," IEEE Transactions on Antennas and Propagation, vol. 35, no. 12, pp. 1351-1357, 1987.

[23] S. R. Rengarajan, L. G. Josefsson, and R. S. Elliott, "Waveguidefed slot antennas and arrays: a review," Electromagnetics, vol. 19, no. 1, pp. 3-22, 1999.

[24] S. R. Rengarajan, "Slot antennas and arrays," Electromagnetics, vol. 19, no. 1, pp. 1-2, 1999.

[25] S. R. Rengarajan, "Improved design procedure for slot array antennas using the mehtod of moments analysis," Electromagnetics, vol. 32, no. 4, pp. 221-232, 2012.

[26] S. R. Rengarajan, M. S. Zawadzki, and R. E. Hodges, "Waveguide-slot array antenna designs for low-averagesidelobe specifications," IEEE Antennas and Propagation Magazine, vol. 52, no. 6, pp. 89-98, 2010.

[27] G. A. Casula, G. Mazzarella, and G. Montisci, "Design of shaped beam planar arrays of waveguide longitudinal slots," International Journal of Antennas and Propagation, vol. 2013, Article ID 767342, 12 pages, 2013.

[28] G. A. Casula, G. Mazzarella, and G. Montisci, "A truncated waveguide fed by a microstrip as a radiating element for highperformance automotive anticollision radars," International Journal of Antennas and Propagation, vol. 2012, Article ID 983281, 9 pages, 2012. 

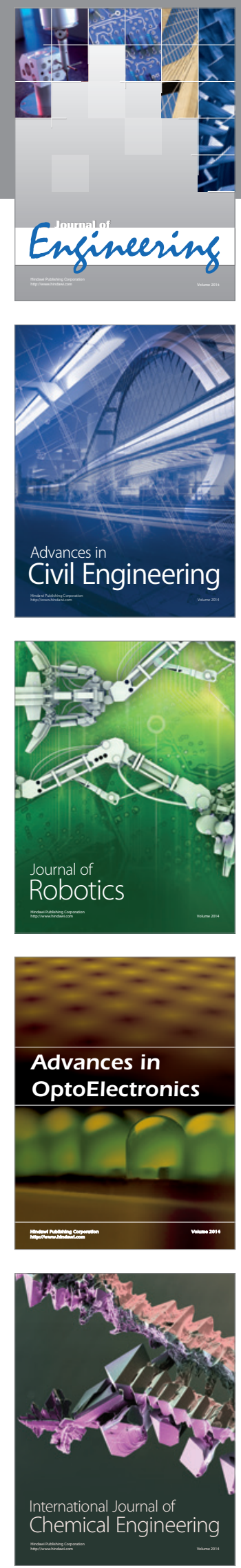

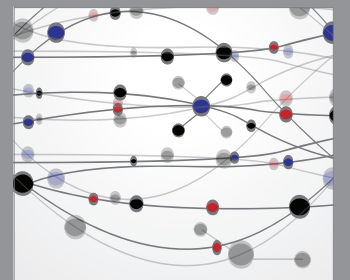

The Scientific World Journal
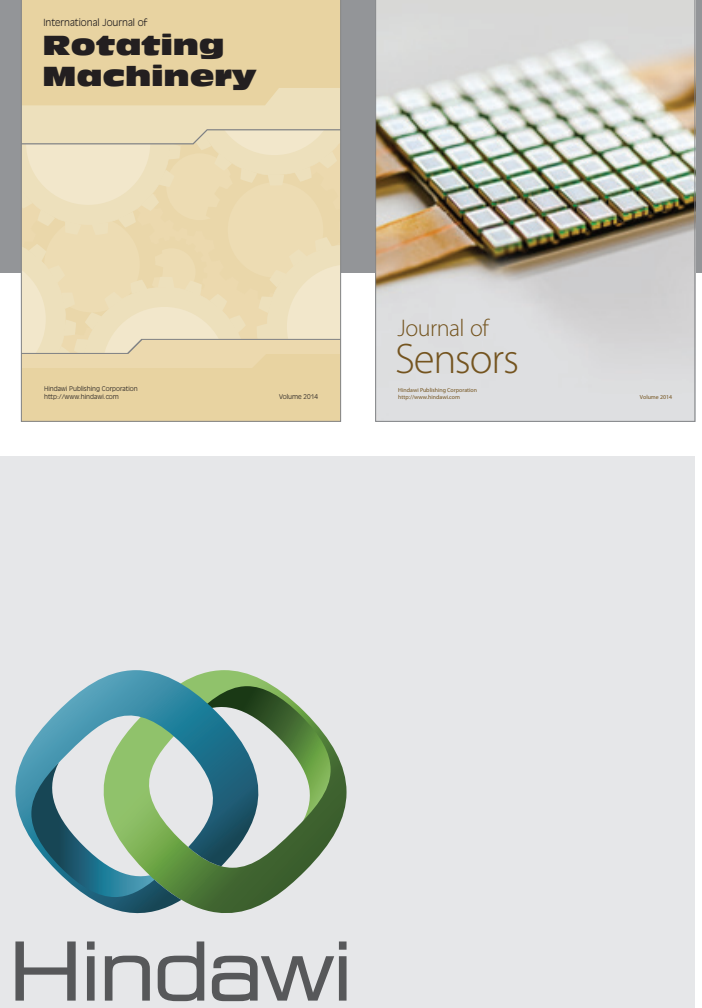

Submit your manuscripts at http://www.hindawi.com
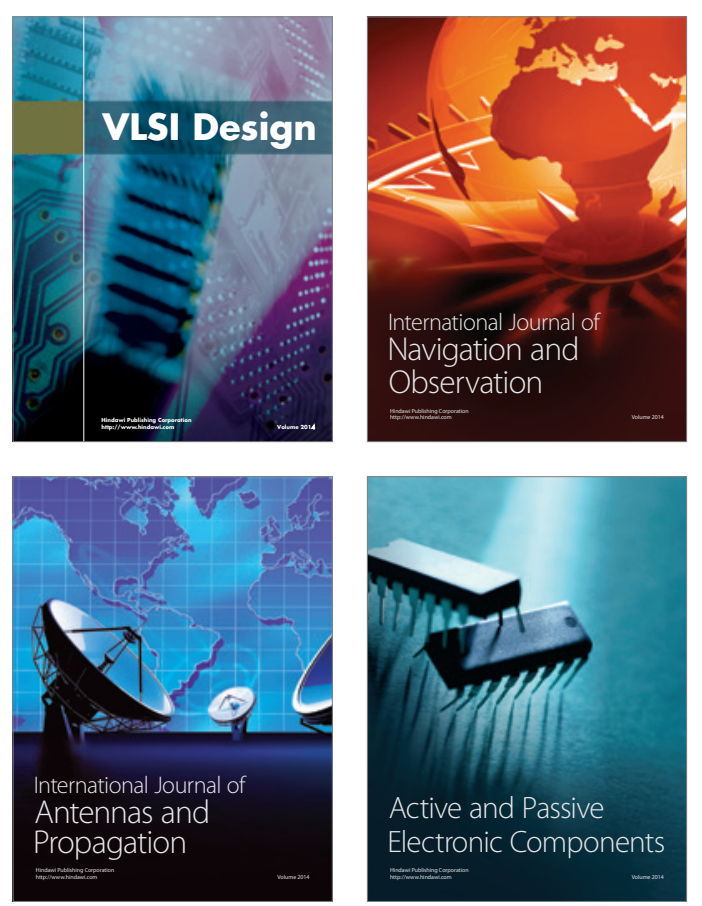
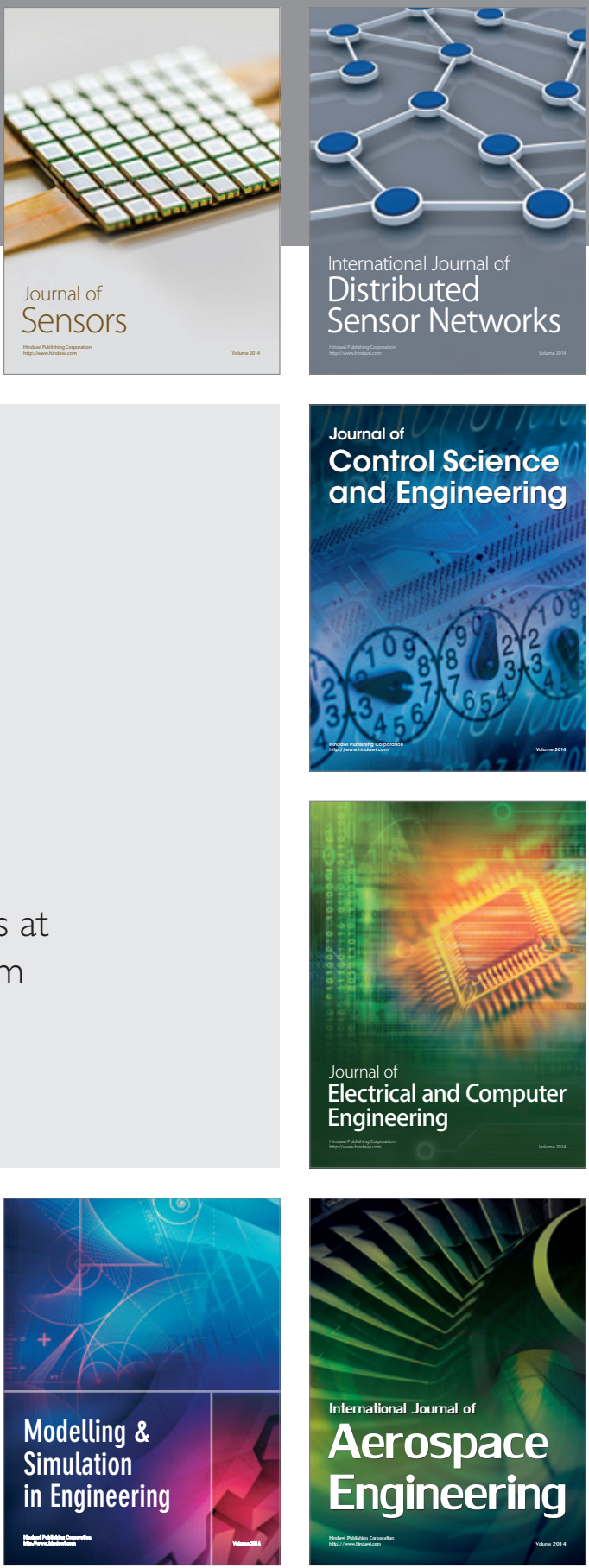

Journal of

Control Science

and Engineering
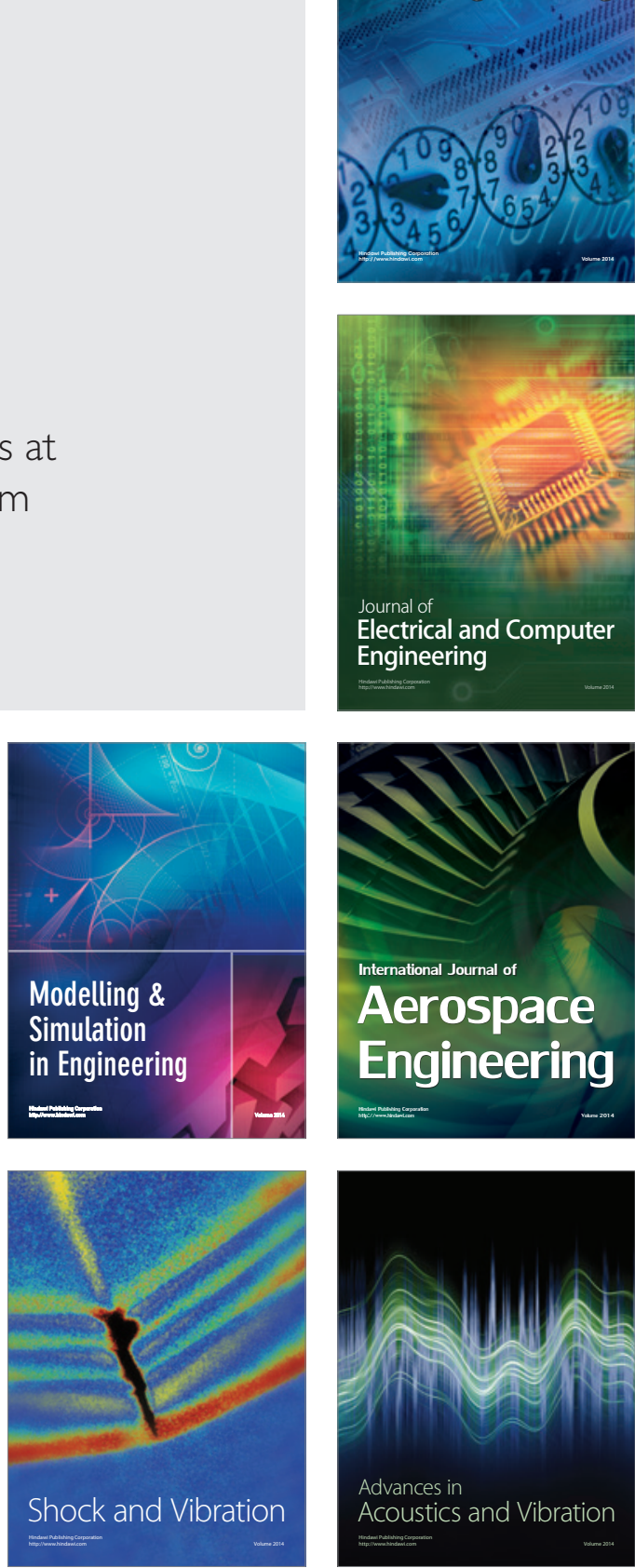